\title{
Nurses' perception in Tehran of Elder Abuse
}

\author{
Bahramnezhad $\mathrm{F}^{1}$, Navab $\mathrm{E}^{* 2}$, Bakhshi $\mathrm{R}^{3}$, Asadi Noghabi AA ${ }^{4}$, Mehran $\mathrm{A}^{5}$
}

\begin{abstract}
Introduction and purpose: Number of elderly population is increasing and according to WHO estimation, this number rise up to $22 \%$ in 2050 . Elderly are prone to several challenges such as elder abuse due to aging population. Therefore, this study aimed to investigate nurses' perception of elder abuse in the city of Tehran.

Materials and Methods: This Cross-sectional study was conducted by convenience sampling method to select 400 nurses from February to March 2014. Samples selected from nurses working in the emergency departments affiliated to Tehran University of Medical Sciences, Tehran, Iran. A researcher-made questionnaire was used and the reliability was ensured using Cronbach's alpha ( $\alpha=82 \%)$. SPSS version 13 was used to analyze the data via descriptive statistics.

Findings: Findings from this study indicated that mean age of our participants was $40.12(\mathrm{SD}=7.05)$ years old. Nurses perceived financial and sexual elder abuse as the most frequent type of elderly abuse.

Conclusion: Nurses spend a large amount of time with patients compared to other health care practitioners which represent nurses as the frontline in proving care to elderly. Therefore, it is necessary to expand our knowledge about elder abuse and different type of abuse.
\end{abstract}

Keywords: Elder abuse, Perception, Old people, Nurse, Tehran

Received: 2016/05/3

Accepted: 2016/09/5

Copyright () 2018 Quarterly Journal of Geriatric Nursing.This is an open-access article distributed under the terms of the Creative Commons Attribution international 4.0 International License(http://creativecommons.org/licenses/by /4.0/) which permits copy and redistribute the material, in any medium or format, provided the original work is properly cited.

1 - BS, Ms, PhD candidate, Critical Care Nursing Department, School of Nursing and Midwifery, Tehran University of Medical Science, Tehran, IR Iran

2 - BS,Ms, PhD, Head of Critical care and Geriatric Nursing, School of Nursing and Midwifery, Tehran University of Medical Sciences, Tehran, IR Iran. (Corresponding Author):E-mail: E-navab@sina.tums.ac.ir 3 - BS, Ms, Geriatric Nursing Department, School of Nursing and Midwifery, Tehran University of Medical Science, Tehran, IR Iran

4 - BS, Ms, PhD,Geriatric Nursing Department, School of Nursing and Midwifery, Tehran University of Medical Science, Tehran, IR Iran

5 - BS,MS, Critical care and Geriatric Nursing Department, School of Nursing and Midwifery, Tehran University of Medical Sciences, Tehran, IR Iran 


\section{درك يرستاران شهر تهران از سوء رفتار با سالمند}

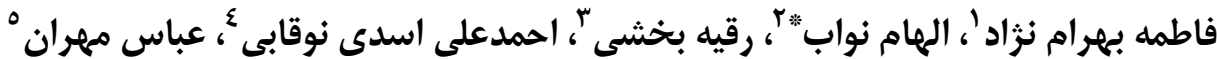

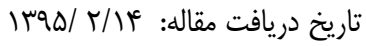
تاريخ پذيرش مقاله: ه| / ع/ هوسا

مقدمه و هدف: با افزايش جمعيت سالمندان ميزان سوء رفتار با آنها در حال افزايش است. عليرغم افزايش اين معضل اما ميزان كزارش دهى آن حتى از سوى كادر درمانى بخصوص يرستاران كه ساعات متمادى با بيمار سيرى مى كنند، بسيار بايين است. هدف اين مطالعه با

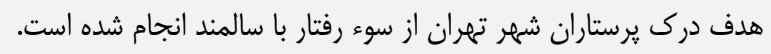

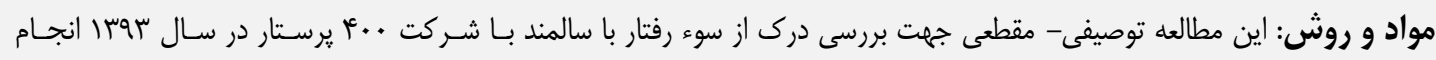

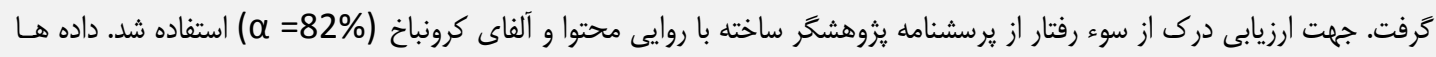
با كمى نرم افزار SPSS نسخهى 9 أو و با كمى آمار توصيفى، تحليل شدند.

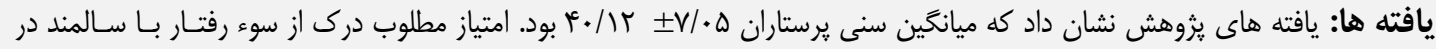

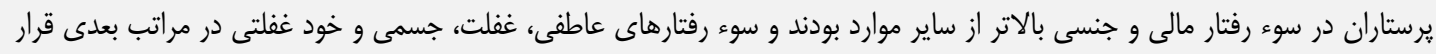
داشتند.

نتيجه گَيرى: با توجه به كسب امتياز پايين در يرستاران در زمينه درك از سوء رفتار با سالمند،ياز به آموزش در اين خصوص ضـرورى

$$
\text { به نظر مى رسد. }
$$
كليد وازه ها: درك، سوء رفتار، سوء رفتار با سالمند، سالمندان، يرستاران، تهران

ا- دانشجوى دكترى آموزش يرستارى، دانشكده يرستارى و مامائى تمران، دانشكاه علوم يزشكى تهران، تهران، ايران

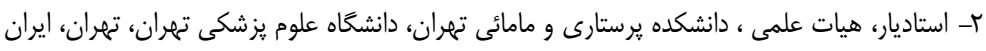

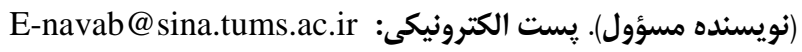

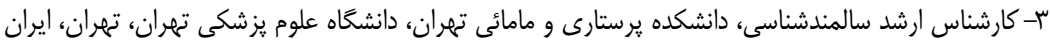

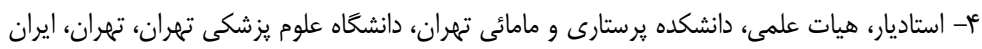

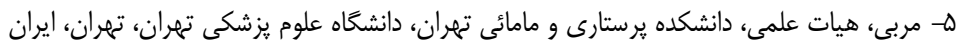


جهانى موارد كزارش شده را بين يك مورد از هر شش مورد تا يك مورد از هر يانزده مورد سوء رفتار برآورد كرده است(·(). عوامل بسيارى بر كم بودن كزارشـات مربـوط بـهـ سـوء رفتـار بـاــا

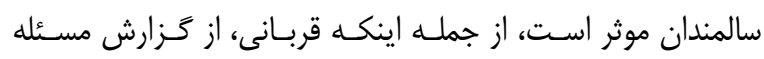
خوددارى كند زيرا به آزار دهنده از نظر نيازهاى حيـاتى يـا از نظـر عاطفى وابستخى دارد و يا ممكـن اسـت تـرس از بيـرون انداختـهـ شدن از خانه و سبرده شدن به موسسات و يا ترس از مورد تلافى واقع شدن، مانع ززارش مسئله شود(1). (1). عدم ززارش سـوء رفتـار همجنين مى تواند به علت سعى سالمند در مراقبـت از سـوء رفتـار كنتده (كه اغلب فردى از خانواده ويا دوستان او مـى باشــ) اتفـاق بيفتد( I).همجِنين سوء رفتار با سالمندان اغلب معضلى است كـه در محدوده اى دور از مشاهده و بررسى ينهان مى مانــ. بـرخلاف كودكان كه خانه را ترك مسى كنــد تـا در مدرسـه حضـور يابنـد، سالمندان در منزل باقى مى مانند، يعنى دقيقا در همان مكانى كـهـ سوء رفتار نهانى در آن آغاز شده است و در آن ادامه مى يابد(سا). يكى ديخــر از مشـكلات شناسـايى مـوارد سـوء رفتـار نسـبت بــــ سالمندان و در واقع مهمترين آنها، فقدان تعريف واضح و روشن از وازه سوء رفتار در اين موارد است. كاركنـان حـرف يزشـكى بـراى شناسايى موارد سوء رفتار نسبت به سالمندان و ييشخيرى از آن به يك تعريف روشن از ماهيت و مفهوم اين ويديـده نيـاز دارنسـ(أ). درى از سوء رفتار بـا سـالمند در سـالمندان در مطالعـات بسـيارى اغلب مورد غفلت قرار گرفتهه است. (ها). درك و تعريف كاركنـان حرفه اي از مفهوم سـوء رفتـار اغلـب بـر ديـدكاه هـاى فـردى و نيازهاى حرفه اى ايشان مبتنى مى باشد(ع).
سوء رفتار با سالمندان شامل خشونت و يا بد رفتارى بـا سـالمندان است كه مى تواند به صورت انجام يا عـدم انجام(غفلـت) رفتـارى

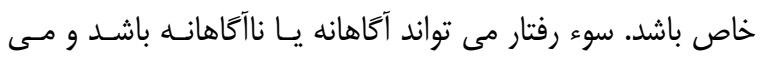
تواند باعث تجاوز به حقوق انسانى و يا كاهش كيفيت زندگى فـرد

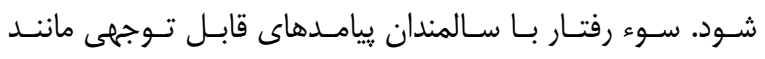
افسردگى، ترس، اضطراب، رنج و درد عـاطفى، صـدمات فيزيكى، سوء تغذيه، كاهش اعتماد به نفس و كاهش طول عمـر سـالمند را

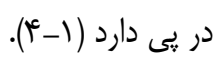
در حسالى كـهـ بسـيارى از صـاحب نظــران نغرانسى عميقـى را در خصوص خشونت در خيابان ها و اماكن عمـومى ابـراز مسى كنــد، متاسفانه احتمال مورد خشونت قـرار گَــفتن افـراد در خـانواده بــه مراتب بيشتر از بيرون خانواده هاست (ه). سوء رفتار بـا سـالمندان به عنوان آخرين شكل تعريف شده خشونت هاى خـانكَى، پِس از همسرآزارى و كودى آزارى براى اولين بار، در سـال 19Va تقريبـاً به طور همزمان، در آمريكا و انغلستان مورد توجه قرار ترفتـ((). هر خند سوء رفتار بـا سـالمندان بــه همـان فراوانسى سـاير اشـكال خشونت هاى خانكى است اما ميزان زَارش و تشخيص آن فـوق

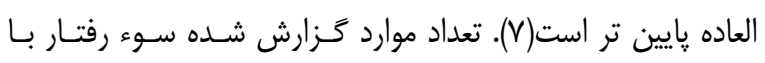
سالمندان در تمامى فرهنگ ها، كمتر از ميزان واقعى آن است. بــه عبارت ديخر رقم سياه بزهكارى(فاصله موجود بين موارد ثبت شده و موارد واقعى) در سوء رفتار با سالمندان بسيار بالاست و فقط يك مورد از هر ده مورد سوء رفتار نسـبت بـهـ سـالمندان كَزارش مسى شود(1, 9). متخصصان معتقدند، آمار رسمى گزارش شده تنها نوى كوه يخِ سوء رفتار با سالمندان را نشان مى دهد. سازمان بهداشت 
بزارگردآورى اطلاعات، يرسشنامه يزوهشخَرساخته بود كه با مـرور متون و مطالعات طراحى گرديد. يرسشنامه شامل دو قسـمت بـود، قسمت اول شامل اطلاعات دموگرافيك مانند سن، جـنس، سـطح تحصـيلات، وضـعيت اقتصـادى ووضـعيت تاهـل و قسـمت دوم يرسشنامه، شامل سوالات مربوط به درك سـوءرفتار بـود. يـس از كسب رضايت آكَاهانسه و بيـان اهــاف يـرُوهش، يرسشـنامه هـا، بصورت خودگزارشى تكميل شدند.

براى روايى يرسشنامه از روايى محتـوا اسـتفاده شـد. بطـورىكـهـ نظرات ده تن از اساتيد دانشكده يرستارى و مامايى دانشگاه تهران در خصوص اين زيرسشنامه اخـــ و اعمـال زرديـد. تعـداد سـوالات يرسشنامه عاب عدد تدوين شـد كـهـ برمبنـاى طيـف ليكرت(كـاملا مخالفم: ا امتياز، مخالفم: r امتياز، نظرى ندارم: ب امتياز، مـوافقه: ك امتياز، كاملا موافقم: ه امتياز) نمره كذارى گرديـد. بطـورى كـهـ كسب نمره بالاتر نشان دهنده درك بالاترى از سوء رفتار با سالمند بود. از ع سوال يرسشنامه س سوال مربوط به سوء رفتارمالى، هفت سوال مربوط به غفلت، r سوال مربوط به سوء رفتار جنسـى و بــه سوء رفتارهاى عاطفى، فيزيكى و خود غفلتـى هـر كـدام أ سـوال اختصاص يافت. جهت محاسبه ييوستخى درونى از آلفاى كرونبـاخ استفاده شد به طورى كه يرسشنامه ى • · نفر از يرستاران انتخاب شده و با استفاده از آزمــون آلفــاى كرونبـاخ و بــا اسـتفاده از ابـزار يايايى آن در يرستاران( SPSS

جهت تجزيه و تحليـل داده هـا از نـرم افـزار SPSS نسـخه 19 استفاده شد. براى دستيابى به اهداف و سـوالات يـروهش، از آمـار توصيفى مانند شاخص هاى آمارى و تنظيم جداول توزيع فراوانى استفاده شد.
طبق مطالعات انجام شده، بـين درك كاركنـان حرفـه اي از سـوء رفتار و گزارش موضوع ارتباط مستقيمى وجود دارد، بدين معنا كـهـ هر جه درك از سوء رفتار صحيح تر باشد، ميـزان خَزارش آن نيـز بيشتر و دقيق ترخواهد بود(IV).

بنا بر مطالب ذكر شده و با توجه بــه اينكـهـ يرسـتاران بـهـ عنـوان قشرى از تيه بهداشت و درمان، كه بيشترين تماس را با مددجويان دارند در موقعيت مناسـبى بــراى تشـخيص، ارزيـابى و مداخلـه در خشونت هـاى خـانكى هسـتند(N|) و نظـر بــه اينكــه در آينـدهى نزديك سالمندان بزرگترين گروه مددجويان را در كشور ما تشكيل خواهند داد و با توجه به نا شناخته بودن ابعاد درك از يديده سـوء رفتار در يرستاران مطالعه حاضر شكل گرفت.

\section{مواد و روش ها}

مطالعه حاضر از نـوع توصـيفىـ- مقطعى در فاصـله فـروردين تـا شهريور سوسا با حجم نمونه +.أ نفر انجـام شـد. نمونـه هـاى يزوهش شامل يرستاران شاغل در بيمارسـتانهـاى منطقـه شـش تهران كه تحت يوشش دانشگاه علوم يزشكى تهران بودند. در اين مطالعه نمونه گَيرى به روش در دسترس انجام شد، بـدين ترتيـب كه جهت نمونه گيرى از بيمارستانهايى كه تحت يوشش دانشگاه علوم يزشكى تهران در اين منطقه بودند، به صورت تصادفى يـى بيمارستان انتخاب و تمام يرستاران داراى معيارهـاى ورود(داشـتن حداقل شش ماه سابقه كار يرستارى و تمايـل بــه پاسـخكَويى بــهـ سوالات) تحت يوشش قرار گرفتند. يـس از نمونـهـ گيـرى از ايـن بيمارستان، يك بيمارستان ديگر انتخاب و به همين روال تا زمـان رسيدن به حجم نمونه مطلوب ادامه داده شد. 
عا درصد از يرستاران اظهار كردند كه در محيط كار خـود، شـاهد سوء رفتار با سالمندان بوده اند كه تنها ب٪ از آنهـا سـوء رفتـار بـاــا سالمند را در محيط كار خود، تزارش داده اند. يافته هـا نشـان داد امتياز مطلوب درك از سوء رفتار بــا سـالمند در يرسـتاران در سـوء رفتار مالى و جنسى بالاتر از سايرين و به دنبال آن سوء رفتارهـاى عاطفى، غفلت،جسمى و خود غفلتى قرار داشتند( جدول شماره().

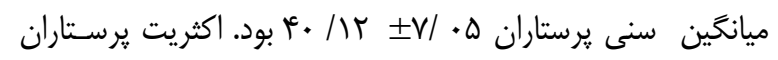
زن و با تحصيلات در سطح كارشناسى بودند (V/ه درصد) و و درصد جمعيت سابقه كارى زير •ا سال را داشـتند. ه/ع درصـد از يرستاران،خودشان از يك سالمند در خانه مراقبت مى كردند و هيج يك از يرستاران شاغل،آموزشى در خصوص سوء رفتار با سالمندان

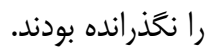

جدول شماره ا: درك از انواع سوء رفتار با سالمند در يرستاران

\begin{tabular}{|c|c|c|c|c|c|c|c|c|c|c|c|c|}
\hline & جنسى & & غفلت & & خود غن & & مالى & & جسمى & & عاطف & انواع سوء \\
\hline درصد & تعداد & درصد & تعداد & درصد & تعداد & درصد & تعداد & درصد & تعداد & درصد & تعداد & امتياز \\
\hline Tr/A & 91 & זץ & 94 & 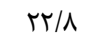 & 91 & $19 / 0$ & $\mathrm{v \wedge}$ & $10 / \mu$ & 81 & re/A & $1 \cdot V$ & ضعيف \\
\hline r/r & WT & $r \cdot / r$ & $\wedge 1$ & 81 & MET & $\mid Q / \Delta$ & st & Trt & ITA & $\mid \Psi / \Delta$ & $\Delta \Lambda$ & متوسط \\
\hline 89 & $r \Delta S$ & $\Delta \& / \Lambda$ & TTV & $19 / \pi$ & 90 & 90 & rg. & $\Delta r / \Lambda$ & rII & $\Delta N / \Lambda$ & טזr & مطلوب \\
\hline $1 \ldots$ & r.. & $1 \ldots$ & f.. & $1 \ldots$ & f.. & $1 .$. & r.. & $1 \ldots$ & $f .$. & $1 \ldots$ & f.. & مجموع \\
\hline
\end{tabular}

\section{بحث و نتيجه كيرى}

يافت نشد. طبق مطالعه اى كـه توسـط Lo و همكـاران بـر روى درى از سوء رفتار با سالمند در دانشـجويان يرسـتارى انجـام داده بودند. دانشجويان در درك از انواع سوء رفتار بــهـ ترتيـب در انـواع جسمى، غفلت، عاطفى، مالى و جنسى امتياز بالاترى كسب كرده بودند كه با مطالعه حاضر متفاوت مى باشد. بــه خصـوص در سـوء رفتار مالى و جنسى كه در مطالعه حاضر بيشترين امتياز را در گروه
يافته هاى مطالعه حاضر نشان داد كه امتياز مطلـوب درك از سـوء رفتار در يرستاران در سوء رفتار مالى و جنسى بـالاتر از سـايرانواع سوء رفتار قرار دارد. طبق مرور متون انجام شده مطالعه اى كه بــــ بررسى درى از انواع سوء رفتار با سالمند در يرستاران بِردازد، 
سوء رفتار مالى يكى از انواع سوء رفتارهايى مسى باشــ كـه طبـق مطالعات انجام شده، بعد از غفلت (DV درصد) و سوء رفتار فيزيكى (19 درصد) درصد قابل توجهى (ه (19 دصد) را بـه خـود اختصـاص مى دهد( (T). در خصوص سوء رفتار مالى با سالمند در مطالعسه ى حاضر مى توان كَفت كه همانند دو سوء رفتار مورد بحث، يرستاران نيز در مورد اين سوء رفتار درك پـايينى داشـتند. كرجـهـه مطالعـاتى درى يرستاران در خصوص يديده ى سوء رفتار با سالمند بيـردازد،

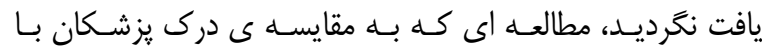
سالمندان يرداخته بود، اين مطالعه ى بيان نمـود كـهـ يزشـكان در خصوص קپيده ى سوء رفتار مالى درى پايين تـرى را نسـبت بـهـ سالمندان دارند(19). در مطالعه اى كه در كره انجام شد تنها حدود r درصد از دانشجويان يرستارى شركت كننده، سوء رفتـار مـالى رال يك نوع سوء رفتار با سالمند مى دانستند( I) • با توجـهـ بـهـ اينكـهـ هو درصد از يرستاران امتياز مطلوبى در خصوص سوء رفتـار مـالى در اين مطالعه كسب كرده بودند، نتايج مطالعه حاضر با اين مطالعه متناقض مى باشد. علت اين امر مى تواند مربوط به تفاوت جوامـع يثروهش مطالعه باشد. مطالعـه Lo در هنــ كنــ انجـام شـــــ و شركت كنندًان آن دانشجويان ثرسـتارى بودنــــ همجنــين سـوء رفتار مالى با ويثگى هاى دموگرافيى و اقتصادى مرتبط مى باشد؛ انجام مطالعاتى كه به بررسى اطلاعات دموكرافيك و سوء رفتار بـاــا سالمند بِردازد، مى تواند مفيد باشد و علل تفاوتها را آشكارتر كند. غفلت يكى از انواع سوء رفتار مى باشد كه درصد قابـل تـوجهى را در مطالعات به خود اختصاص مى دهد و تقريبا مى توان كفت كـهـ نيمى از سوء رفتارها از اين نوع مى باشـند( (r). مطالعـه ى حاضـر نشان داد كه يرستاران درى كمى از اين نوع سوء رفتـار داشـتند. بر اساس مرور متون انجام شده، مطالعه اى كه درك يرستاران را
يرستاران كسب كرد(؟I). در اين بخش مى توان كفت، تفـاوت در يرسشنامه استفاده شده و يكسان نبودن شــت سـوالات در انـواع سوء رفتار مى تواند موجب تفاوت در امتيازات كسـب شــه باشـــ. همجنين متفاوت بودن جامعـه يـزروهش (يرسـتاران و دانشـجويان يرستارى) و تفاوت فرهنگى جوامع (تهران و هنَ كنحَ) نيز مى تواند در اين تفاوت موثر مى باشد.

مطابق با يافته هاى مطالعـهى حاضـر، يرسـتاران درى پـايينى از

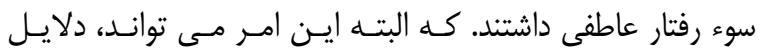
مختلفى داشته باشد. بر اساس مرور متونى كه انجام كرفت،مطالعه اى كه به بررسى درك سوء رفتـار روانشـناختى در بـين يرسـتاران بيردازد، يافت نشد. در مطالعه اى كه به مقايسه درك از سوء رفتـار عاطفى بين سالمندان و يزشكان پرداختـه، يزشـكان امتيـاز پـايين ترى در درى از سوء رفتار عاطفى با سالمند به دست آوردنـد(19). يزوهشگر اين احتمال را مىدهد از آنجا كه سوءرفتارعاطفى،علايم عينى بر فردسالمند ندارد، اين عينـى نبـودن ممكـن اسـت باعـث كـاهش ميـزان تشـخيص و درك از رنجـى كـه سـالمند در ايـن خصوص متحمل مى شود، باشد. سوء رفتار فيزيكى يكى از انواع سوء رفتـار مسى باشـــــه علايـمم مشخصى را داشته و نسبت به سوء رفتار روانشناختى يى بردن بــه اين مسئله راحتتر مى باشد. عليرغم عينى بودن اين سـوء رفتـار و وجود علايم اعلام شــه از طـرف مطالعـات انجـام شــه در ايـن خصوص(·)، در مطالعه ى حاضر يرستاران درى كمى نسبت بــه

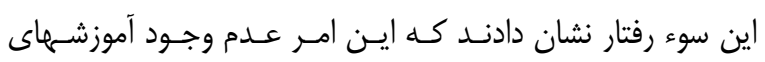
مناسب در اين زمينه را نشان مى دهد. 
يرستاران نسبت به ساير اعضاى تيم بهداشـت و درمـان بيشـترين

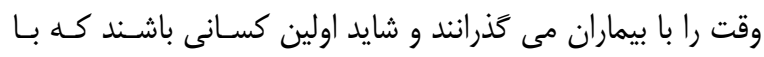
مراجعين برخورد مى كنند. با افزايش جمعيت سالمندان در ايـران، تعداد مراجعين سالمند نيز افزايش داشته است. يرستاران مى توانند در ييشگيرى از سوء رفتار با سالمند، بالا بردن مهارتهاى تشخيص سوء رفتار با سالمند و آموزش عموم جامعه در خصوص اين بديـده فعالانه تلاش كنند. آموزش يرستاران مى تواند در افزايش دانش و درك يرستاران در خصوص سوء رفتار با سالمند كمى كننده باشـــ و در نهايت باعث افزايش مهارت يرستاران در مداخله در خصـوص سوء رفتار با سالمند گردد. از محدوديتهاى اين يزوهش مسى تـوان به به علت بالا بودن حجم نمونه، نمونه گيرى به صورت تصـادفى انجام نشد و به روش آسان و دسترس انجـام شـد، همجنـين ايـنـ مطالعه تنها در منطقه شش تهران بدون در نظر نغَرفتن تفاوتهـاى اقتصادى - اجتماعى منطقه ى شش تهران با ساير منـاطق انجـام شد. گَرجه اين مطالعه بر روى انجام گرفت، ولى مرور متون انجام

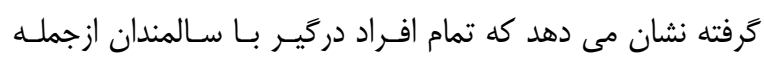
يزشكان، مراقبين نيز نياز به آموزش در اين زمينـه دارنـــــــابراين ييشنهاد مى كَدد مطالعه بر روى ساير گَروههاى دركير نيز انجـام شود. همجِنين ميتوان مطالعاتى در خصـوص سـالمندان سـاكن در خانه هاى سالمندان انجام داد. اين مطالعه تنها به بررسى درى از سوء رفتار با سالمند برداخته اسـت مطالعـات آتـى مـى توانتـــ بــــ بررسى شيوع سوء رفتار با سالمند، علل و عوامل خطر مرتبط با آن بيردازند. حتى يِيشنهاد مى شود كه شيوع سوء رفتـار بـا سـالمند و ييامدهاى آن به صورت يك طرح ملى انجام شود.
نسب به اين نوع سوء رفتار مورد بررسى قرار دهد، يافت نشد. البته در مطالعه اى كه به مقايسه درك از سوء رفتار با سـالمند در ميـان يزشكان انجام شد أنها نيز همانند مطالعهى حاضـر درى يـايينى نسبت به اين سوء رفتار با سالمند داشتند(19). خود غفلتى در مطالعات مربوط به سوء رفتار با سالمند اغلب مـورد بى توجهى قرار كَرفته است. اين در حالى مى باشد كه طبق تعريف سازمان بهداشت جهانى، خودغفلتى از انواع سوء رفتـار بـا سـالمند محسوب مى شود (f). مطالعه حاضر نشان داد كه يرستاران درى كمى نسبت به خود غفلتى داشتند كه نشان دهنده نياز به آمـوزش يرستاران در اين خصوص مى باشد. در خصوص درى از سوء رفتار جنسى با سالمند، مطالعه اى كه بــه بررسى درى دانشجويان يرستارى در هنــ كنــ از انـواع سـوء رفتار با سالمند مى يرداخت، فقط ه/ درصــ از دانشـجويان سـال سوم شركت كننده سوء رفتار جنسـى را يـك نـوع سـوء رفتـار بـاــا سالمند مى دانستند و هيجِكدام از دانشجويان سـال يـك شـركت

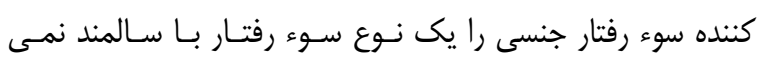
دانستند(r). (1). با توجه به اينكه در مطالعه حاضر بَه درصد يرستاران امتياز مطلوبى از سوء رفتار جنسى به دست آوردنــ نتـايج مطالعـه حاضر برخلاف اين مطالعه مى باشد. برخى از مطالعات انجام شـده در خصوص سوء رفتار با سالمند به علت مسايل فرهنكى به مسئله سوء رفتار جنسى نيرداخته بودند. به طور كلى سوء رفتار با سـالمند مسئله اي وابسته به فرهنَ مى باشد كـهـ ايـن موضـوع در سـوء رفتار جنسى خود را ير رنخ تر نشان مى دهد و نياز بـه مطالعـات بيشترى را طلب مى كند. 


$$
\begin{aligned}
& \text { اين مطالعه بخش از پايان نامه كارشناسى ارشد دانشكده يرستارى } \\
& \text { و مامائى تهران به شماره 17730-98-93-93 بوده است. بدين } \\
& \text { وسيله برخود لازم مى دانيم از همكارى مجدانه معاونت يزوهشى } \\
& \text { دانشـكده يرسـتارى و مامـايى دانشـخاه علـوم زيزشـكى تهــران و } \\
& \text { يرستارانى كه در اين مطالعه ما را يـارى نمودنــ، كمـال امتنـان و }
\end{aligned}
$$

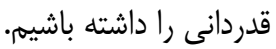

\section{- References}

1. Donovan K, Regehr C. Elder abuse: Clinical, ethical, and legal considerations in social work practice. Clinical Social Work Journal. 2010;38(2):174-82.

2 Lowenstein A. Caregiving and elder abuse and neglect—developing a new conceptual perspective. Ageing International. 2010;35(3):215-27.

3. Schofield MJ, Mishra GD. Three year health outcomes among older women at risk of elder abuse: Women's Health Australia. Quality of Life Research. 2004;13(6):1043-52.

4. Asgari P, Bahramnezhad F, Mehrdad N, Noughabi AAA, Hekmatpou D, Mahmoudi M. Depression, Functionality and Adaptability of Elderly Patients After Open Heart Surgery Off-or On-Pump. Jundishapur Journal of Chronic Disease Care. 2015;4(4.(

5. Pournaghash S. Study of domestic violence in Tehran,. Tehran :Daneshvar; 2004.

6. Erlingsson C, Carlson S, Åström S, Saveman B-I. Dilemmas in witnessing elder abuse in caregiving situations: a family member perspective. Southern Online Journal of Nursing Research. 2009;9(1.(

7. Cooley-Strickland M, Quille TJ, Griffin RS, Stuart EA, Bradshaw CP, Furr-Holden D. Community violence and youth: Affect, behavior, substance use, and academics. Clinical child and family psychology review. 2009;12(2):127-56.

8. Cooper C, Selwood A, Livingston G. The prevalence of elder abuse and neglect: a systematic review. Age and ageing. 2008;37(2):151-60. 
9. Afshar PF, Asgari P, Shiri M, Bahramnezhad F. A Review of the Iran's elderly status according to the census records. Galen Medical Journal. 2016;5(1):1-6.

10. Gorbien MJ, Eisenstein AR. Elder abuse and neglect: an overview. Clinics in geriatric medicine. 2005;21(2):279-92.

11. Daly JM, Merchant ML, Jogerst GJ. Elder abuse research: A systematic review. Journal of Elder Abuse \& Neglect. 2011;23(4):348-65.

12. Lo SKL, Lai CKY, Tsui CM .Student nurses' perception and understanding of elder abuse. International journal of older people nursing. 2010;5(4):283-9.

13. Heravi-Karimooi M, Rejeh N, Foroughan M, Ebadi A. Designing and determining psychometric properties of the Elder Neglect Checklist. Iranian Journal of Ageing. 2013;8(30):25-34.

14. Anetzberger GJ. The reality of elder abuse. Clinical Gerontologist. 2005;28(1-2):1-25.

15. Glendennina F, Kingston P. Elder Abuse and Neglect in Residential Settings: different national backgrounds and similar responses: Routledge; 2014.

16. Heravi M, Milani M, Faghihzade S. The effect of family counseling in preventing the abuse of older women. Hayat. 2005;24(3):77-9(Persian.(

17. Chan KL, Brownridge DA, Fong DY, Tiwari A, Leung WC, Ho PC. Violence against pregnant women can increase the risk of child abuse: A longitudinal study. Child abuse \& neglect. 2012;36(4):275-84.

18. Almogue A, Weiss A, Marcus E-L, Beloosesky Y. Attitudes and knowledge of medical and nursing staff toward elder abuse. Archives of gerontology and geriatrics. 2010;51(1):86-91.

19. Helmes E, Cuevas M. Perceptions of elder abuse among Australian older adults and general practitioners. Australasian Journal on Ageing. 2007;26(3):120-4.

20. Fulmer T, Anetzberger G. Knowledge about family violence interventions in the field of elder abuse. Unpublished paper for the Committee on the Assessment of Family Violence Interventions of the National Research Council and Institute of Medicine. 1995.

21. Kennedy RD. Elder abuse and neglect: the experience, knowledge, and attitudes of primary care physicians. FAMILY MEDICINE-KANSAS CITY-. 2005;37(7):481. 